CLINICAL STUDY

\title{
Thyreotropin levels in diabetic patients on metformin treatment
}

Carlo Cappelli, Mario Rotondi ${ }^{1}$, Ilenia Pirola, Barbara Agosti $^{2}$, Annamaria Formenti, Emanuela Zarra ${ }^{2}$, Umberto Valentini ${ }^{2}$, Paola Leporati ${ }^{1}$, Luca Chiovato ${ }^{1}$ and Maurizio Castellano

Endocrine and Metabolic Unit, Department of Medical and Surgical Sciences, Clinica Medica, University of Brescia, c/o 1 Medicina Spedali Civili Piazzale Spedali Civili 1, 25100 Brescia, Italy, ${ }^{1}$ Unit of Internal Medicine and Endocrinology, Fondazione Salvatore Maugeri, I.R.C.C.S., INAIL Laboratory for Endocrine Disruptors and Chair of Endocrinology, University of Pavia, Pavia, Italy and ${ }^{2}$ Diabetic Unit, Spedali Civili di Brescia, Brescia, Italy

(Correspondence should be addressed to C Cappelli; Email: cappelli@med.unibs.it)

\begin{abstract}
Objective: A retrospective study to evaluate the changes in TSH concentrations in diabetic patients treated or not treated with metformin and/or L-thyroxine $\left(\mathrm{L}-\mathrm{T}_{4}\right)$.

Methods: Three hundred and ninety three euthyroid diabetic patients were divided into three groups on the basis of metformin and/or $\mathrm{L}_{-} \mathrm{T}_{4}$ treatment: Group $(\mathrm{M}-/ \mathrm{L}-), 119$ subjects never treated with metformin and $\mathrm{L}_{-} \mathrm{T}_{4}$; Group $(\mathrm{M}+/ \mathrm{L}-), 203$ subjects who started metformin treatment at recruitment; and Group $(\mathrm{M}+/ \mathrm{L}+), 71$ patients on $\mathrm{L}_{-} \mathrm{T}_{4}$ who started metformin recruitment.

Results: The effect of metformin on serum TSH concentrations was analyzed in relation to the basal value of TSH (below $2.5 \mathrm{mIU} / \mathrm{l}(\mathrm{Q} 1)$ or between 2.51 and $4.5 \mathrm{mIU} / \mathrm{l}(\mathrm{Q} 2)$ ). In patients of group $\mathrm{M}+/ \mathrm{L}+$, TSH significantly decreased independently from the basal level $(\mathrm{Q} 1$, from $1.45 \pm 0.53$ to $1.01 \pm 1.12 \mathrm{mU} / \mathrm{l}(P=0.037) ; \mathrm{Q} 2$, from $3.60 \pm 0.53$ to $1.91 \pm 0.89 \mathrm{mU} / \mathrm{l}(P<0.0001))$. In $\mathrm{M}+/ \mathrm{L}-$ group, the decrease in TSH was significant only in those patients with a basal high-normal serum TSH (Q2: from $3.24 \pm 0.51$ to $2.27 \pm 1.28 \mathrm{mU} / \mathrm{l}(P=0.004))$; in $\mathrm{M}-/ \mathrm{L}-$ patients, no significant changes in TSH levels were observed.

In patients of group $\mathrm{M}+/ \mathrm{L}-$ showing high-normal basal TSH levels, a significant decrease in TSH was observed independently from the presence or absence of thyroid peroxidase antibodies (AbTPO; Q2 AbTPO + : from 3.38 \pm 0.48 to $1.87 \pm 1.08 \mathrm{mU} / \mathrm{l}(P<0.001)$; Q2 AbTPO - : from $3.21 \pm$ 0.52 to $2.34 \pm 1.31 \mathrm{mU} / \mathrm{l}(P<0.001))$.

Conclusions: These data strengthen the known TSH-lowering effect of metformin in diabetic patients on $\mathrm{L}^{-} \mathrm{T}_{4}$ treatment and shows a significant reduction of TSH also in euthyroid patients with higher baseline TSH levels independently from the presence of AbTPO.
\end{abstract}

European Journal of Endocrinology 167 261-265

\section{Introduction}

Diabetes mellitus and thyroid disorders represent the two most frequent endocrinopathies encountered in clinical practice, with an estimated prevalence in the general population around 4 and $6 \%$ respectively $(1,2)$. Both conditions frequently coexist and the prevalence of thyroid dysfunction in diabetic patients appears to be higher than in the general population $(3,4)$, ranging from 10 to $30 \%(5,6)$.

Metformin is a widely used drug for the treatment of diabetes mellitus, not only in patients with the type 2 disease $(7,8)$ but also in adults and adolescents affected by diabetes mellitus type 1 when insulin resistance is present $(9,10)$.

Previous studies from the literature, including those from our groups, indicate that metformin influences the serum levels of TSH by lowering the circulating concentrations of the pituitary hormone to a subnormal level in hypothyroid patients $(11,12)$ treated with L-thyroxine $\left(\mathrm{L}-\mathrm{T}_{4}\right)$ at substitution doses. We also reported a significant reduction of serum TSH levels in diabetic patients with primary untreated hypothyroidism (13). More recently, a decrease in serum TSH was also observed in hypothyroid women being treated with metformin for a coexistent polycystic ovarian syndrome $(14,15)$.

The aim of this study was to evaluate the changes in serum TSH concentrations in a large series of diabetic patients being treated or not treated with metformin and/or $\mathrm{L}-\mathrm{T}_{4}$.

\section{Patients and methods}

Diabetic patients were recruited by searching the computerized database of subjects treated and followed at the Diabetic Unit of the Department of Medical and Surgical Sciences, University of Brescia. Searching criteria were as follows: i) complete personal medical history; ii) detailed current drug treatment and any previous change; iii) thyroid hormone profile at 
recruitment and then every year; and iv) a follow-up period of at least 1 year.

Among 7020 subjects, a total of 393 euthyroid diabetic patients were collected and divided into three groups on the basis of metformin and/or $\mathrm{L}^{-} \mathrm{T}_{4}$ treatment:

- Group $(\mathrm{M}-/ \mathrm{L}-)$ : 119 subjects never treated with metformin and $\mathrm{L}-\mathrm{T}_{4}$.

- Group (M+/L-): 203 subjects who started metformin treatment at recruitment.

- Group $(\mathrm{M}+/ \mathrm{L}+)$ : 71 patients on $\mathrm{L}_{-} \mathrm{T}_{4}$ who started metformin treatment at recruitment.

\section{Laboratory assay}

Serum concentrations of free $\mathrm{T}_{4}\left(\mathrm{fT}_{4}\right.$; normal range: 8.0-19.0 pg/ml) and TSH (third generation TSH assay; normal range: $0.4-4.5 \mathrm{mIU} / \mathrm{l})$ were measured using immunochemiluminescent assays by an automated analyzer (Immulite 2000, DPC Cirrus, Los Angeles, CA, USA) using commercial kits (Diagnostic Products Corporation, Los Angeles, CA, USA). The serum concentrations of thyroid peroxidase antibodies (AbTPO; normal range: $<60 \mathrm{U} / \mathrm{ml}$ ) were measured using immunochemiluminescent assays using commercial kits (Brahms, Hennigsdorf, Germany).

\section{Statistical analysis}

Between- and within-group comparisons were performed by ANOVA general linear model, including repeated measures analysis. $\chi^{2}$ test was used for between-group comparisons of categorical variables. All data were analyzed using SPSS version 17 (SPPS, Inc., Chicago, IL, USA). Data are expressed as mean \pm S.D. unless otherwise stated. Statistical significance was considered at $P<0.05$.

\section{Results}

Among 7020 diabetic patients included in the computerized database, 393 subjects ( 255 females and 138 males, mean age $54.1 \pm 11.2$ years) satisfied the above inclusion criteria: $34(8.7 \%)$ patients were affected by type 1 diabetes mellitus and $359(91.3 \%)$ by type 2 diabetes. Seventy-one $(18.1 \%)$ patients were euthyroid on L-T ${ }_{4}$; among them, $60(84.5 \%)$ had Hashimoto's thyroiditis, $10(14.1 \%)$ had been treated with thyroidectomy for benign thyroid diseases, and one (1.4\%) had an amiodarone-induced hypothyroidism.

Clinical data of patients subdivided in the three groups according to their drug therapy at recruitment are shown in Table 1. The three patient groups did not significantly differ in age, BMI, and smoking habits at recruitment, but a higher prevalence of men was
Table 1 Clinical data of patients according to their drug therapy at recruitment.

\begin{tabular}{lccc}
\hline & Group $\mathbf{M}+/ \mathbf{L}-$ & Group $\mathbf{M}+/ \mathbf{L}+$ & Group $\mathbf{M}-\mathbf{L}-$ \\
\hline Patients $(n)$ & 203 & 71 & 119 \\
Gender (M/F) & $87 / 116$ & $14 / 57$ & $60 / 59$ \\
Age (years) & $52 \pm 7.1$ & $53.2 \pm 6.8$ & $55 \pm 7.2$ \\
$\mathrm{BMI}\left(\mathrm{kg} / \mathrm{m}^{2}\right)$ & $32.6 \pm 5.4$ & $31.3 \pm 4.4$ & $33.1 \pm 4.7$ \\
Smokers $(n)$ & $70 / 203$ & $24 / 71$ & $41 / 119$ \\
$\mathrm{TSH}(\mathrm{mlU} / \mathrm{l} /)$ & $2.07 \pm 1.43$ & $2.16 \pm 1.19$ & $1.67 \pm 0.84^{*, \dagger}$ \\
$\mathrm{fT}_{4}(\mathrm{pg} / \mathrm{ml})$ & $12.4 \pm 1.7$ & $12.6 \pm 1.4$ & $12.4 \pm 2.0$ \\
Metformin & $1735 \pm 659.8$ & $1747 \pm 611.2$ & - \\
$\quad(\mathrm{mg} /$ day) & & & - \\
$\mathrm{L}-\mathrm{T}_{4}(\mu \mathrm{g} /$ day) & - & $88.7 \pm 15.4$ & - \\
\hline
\end{tabular}

${ }^{\star} P<0.05$ vs group $\mathrm{M}+/ \mathrm{L}+.{ }^{\dagger} P<0.001$ vs group $\mathrm{M}+/ \mathrm{L}-$.

observed in the $\mathrm{M}-/ \mathrm{L}-$ group. Patients affected by type 1 diabetes mellitus were similarly distributed among the three groups (18/203 (8.8\%) in $\mathrm{M}+/ \mathrm{L}+$ group, $6 / 71$ $(8.4 \%)$ in $\mathrm{M}+/ \mathrm{L}-$ group, and $10 / 119(8.4 \%)$ in $\mathrm{M}-$ $/ \mathrm{L}-$ group respectively). Significantly lower values of serum TSH were observed in $\mathrm{M}-/ \mathrm{L}-$ patients, whereas serum $\mathrm{fT}_{4}$ levels were superimposable among the groups. Positive tests for circulating AbTPO were found in 39/203 (19.2\%), 65/71 (91.5\%), and $21 / 119$ (17.6\%) patients in $M+/ L-, M+/ L+$, and $\mathrm{M}-/ \mathrm{L}-$ groups respectively.

When considered as a whole group, after 1 year of follow-up, no significant change in serum levels of TSH $\left(1.83 \pm 0.96\right.$ vs $1.75 \pm 1.25$, NS), serum levels of $\mathrm{fT}_{4}$ $(11.9 \pm 1.2$ vs $12.1 \pm 1.1$, NS), and BMI (32.1 \pm 4.5 vs $32.7 \pm 3.4$, NS) was observed. Multiple regression analysis with TSH serum levels at 1-year follow-up as dependent variable showed that metformin treatment was related to TSH decrease. Age, gender, smoking habits, BMI, and $\mathrm{L}_{-} \mathrm{T}_{4}$ treatment were nonsignificant variables in this model (Table 2).

The serum levels of TSH at baseline and after 1 year in the three groups of patients are shown in Fig. 1. TSH levels decreased in patients undergoing metformin treatment, but statistical significance was reached only in those receiving $\mathrm{L}-\mathrm{T}_{4}$ (from $2.16 \pm 1.18$ to $1.33 \pm$ $1.12 \mathrm{mU} / \mathrm{l}(P<0.001))$. Moreover, $3 / 203(1.5 \%)$ subjects of $\mathrm{M}+/ \mathrm{L}-$ group and $6 / 71(8.4 \%)$ of $\mathrm{M}+/ \mathrm{L}+$ group showed undetectable serum TSH levels at the end of the study. A slight but not significant increase in serum TSH levels was observed in $\mathrm{M}-/ \mathrm{L}-$ group (from

Table 2 Multiple regression analysis for TSH serum levels at 1 year of follow-up as dependent variable in the whole group of euthyroid diabetic patients.

\begin{tabular}{lrrrr}
\hline Variable & $\boldsymbol{B}$ & \multicolumn{2}{c}{$\mathbf{9 5 \%} \mathbf{C l}$} & $\boldsymbol{P}$ value \\
\hline Female & 0.029 & -0.023 & 0.081 & 0.269 \\
Age & 0.007 & -0.032 & 0.157 & 0.161 \\
BMl & 0.124 & -0.005 & 0.060 & 0.151 \\
Smokers & 0.083 & 0.025 & 0.190 & 0.130 \\
Metformin & -0.449 & -0.747 & -0.151 & 0.031 \\
$\mathrm{~L}-\mathrm{T}_{4}$ & -0.192 & -0.747 & -0.151 & 0.286 \\
\hline
\end{tabular}




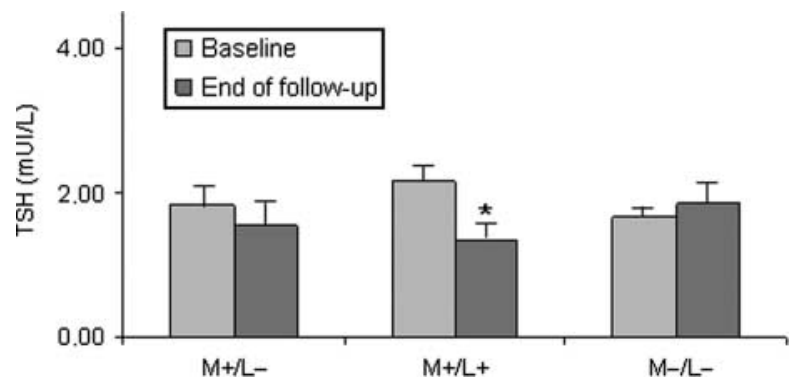

Figure $1 \mathrm{TSH}$ levels at baseline and at the end of the study in each group. ${ }^{*} P<0.001$ vs baseline.

$1.67 \pm 0.84$ to $1.85 \pm 1.35 \mathrm{mU} / \mathrm{l})$. None of the patients developed hyperthyroidism. Serum $\mathrm{fT}_{4}$ concentrations did not change in any group of patients from baseline to the end of the follow-up $(\mathrm{M}+/ \mathrm{L}-$ group, $12.4 \pm 1.7 \mathrm{vs}$ $12.6 \pm 1.9(P=0.264) ; \mathrm{M}+/ \mathrm{L}+$ group, $12.6 \pm 1.4$ vs $12.9 \pm 2.3(P=0.349) ;$ and $M-/ L-$ group, $12.4 \pm 2.0$ vs $12.7 \pm 2.3(P=0.284)$ respectively $)$. Similarly, no change in mean BMI value was observed from baseline to the end of follow-up in any group $(\mathrm{M}+/ \mathrm{L}-$ group, $32.6 \pm 5.4$ vs $32.3 \pm 4.7(P=0.623) ; \mathrm{M}+/ \mathrm{L}+$ group, $31.3 \pm 4.4$ vs $30.9 \pm 4.5(0.354)$; and $\mathrm{M}-/ \mathrm{L}-$ group, $33.1 \pm 4.7$ vs $32.9 \pm 3.8(P=0.687)$ respectively). In order to evaluate the effect of metformin on serum TSH levels in relation to the basal level of pituitary hormone, all patients were stratified according to a serum TSH value below $2.5 \mathrm{mIU} / \mathrm{l}(\mathrm{Q} 1)$ or between 2.51 and $4.5 \mathrm{mIU} / \mathrm{l}(\mathrm{Q} 2)$.

Following stratification, a significantly different behavior emerged in the three groups (Fig. 2). Indeed, in patients of $\mathrm{M}+/ \mathrm{L}+$ group, the serum concentration of TSH significantly decreased independently from its value at baseline $(\mathrm{Q} 1$, from $1.45 \pm 0.53$ to $1.01 \pm$ $1.12 \mathrm{mU} / \mathrm{l}(P=0.037) ; \mathrm{Q} 2$, from $3.60 \pm 0.53$ to $1.91 \pm$ $0.89 \mathrm{mU} / \mathrm{l}(P<0.0001))$.

On the other hand, in patients of $\mathrm{M}+/ \mathrm{L}-$ group, a significant decrease in serum TSH (Q2: from
$3.24 \pm 0.51$ to $2.27 \pm 1.28 \mathrm{mU} / \mathrm{l}(P=0.004))$ was observed only in those patients with a high-normal basal serum TSH $(>2.5 \mathrm{mU} / \mathrm{l})$. The serum levels of TSH remained unchanged in patients with a basal TSH $\leq 2.5 \mathrm{mU} / \mathrm{l}$. In patients of $\mathrm{M}-/ \mathrm{L}-$ group, no significant change in the serum levels of TSH was observed throughout the study span independently of the basal TSH level.

Patients of $\mathrm{M}+/ \mathrm{L}-$ group were further stratified according to the presence or absence of positive tests for AbTPO. No significant difference was found in the behavior of TSH between patients with detectable or undetectable AbTPO levels (Fig. 3). Only those subjects with high-normal TSH levels, independently from the presence or not of AbTPO, showed a significant decrease in serum thyrotropin $(\mathrm{Q} 2 \mathrm{AbTPO}+$, from $3.38 \pm 0.48$ to $1.87 \pm 1.08 \mathrm{mU} / \mathrm{l}(P<0.01) ; \mathrm{Q} 2 \mathrm{AbTPO}-$, from $3.21 \pm 0.52$ to $2.34 \pm 1.31 \mathrm{mU} / \mathrm{l}(P<0.001))$.

\section{Discussion}

The results of the present retrospective study indicate that the TSH-lowering effect of metformin, previously observed in hypothyroid subjects (13), also occurs in euthyroid diabetic patients with basal TSH in the uppernormal range. This effect of metformin appears to occur independently of the presence of AbTPO.

Metformin is commonly regarded as a safe drug in that clinically relevant pharmacological interactions have not been described when metformin is associated with commonly used drugs, with the exceptions of folate and B12 vitamin $(16,17)$.

Vigersky et al. (11) reported for the first time in 2006 that metformin may interfere with thyroid status, by decreasing the circulating levels of TSH in hypothyroid patients receiving a stable substitution dose of $\mathrm{L}-\mathrm{T}_{4}$. This observation was confirmed by Isidro et al. (12). In a previous study, we showed that treatment with metformin is associated with a significant reduction in the serum levels of TSH in diabetic patients with primary hypothyroidism both untreated and on $\mathrm{L}-\mathrm{T}_{4}$
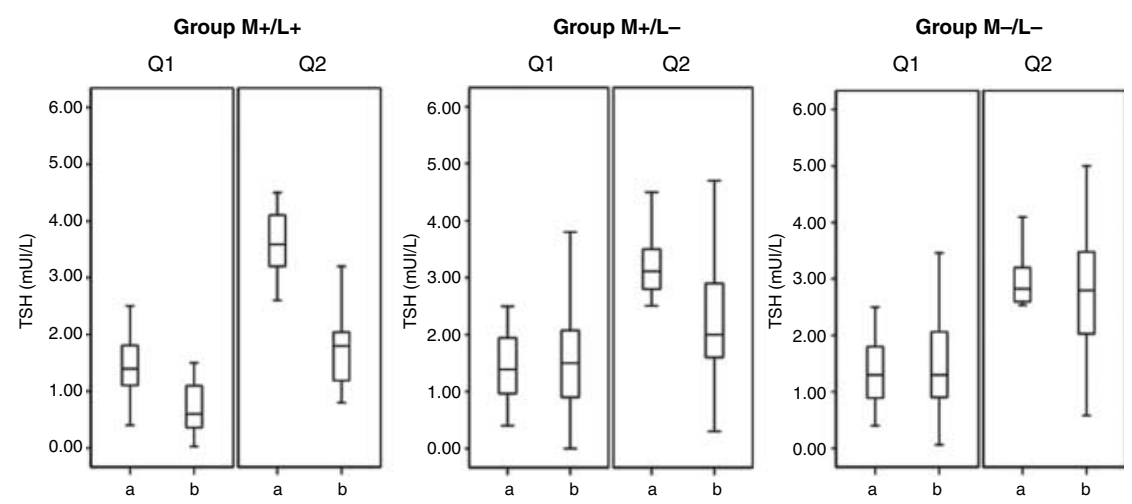

Figure 2 The effect of metformin on serum TSH concentrations in relation to the basal value of TSH among the groups of patients. $a$, baseline; $b$, at the end of follow-up. 

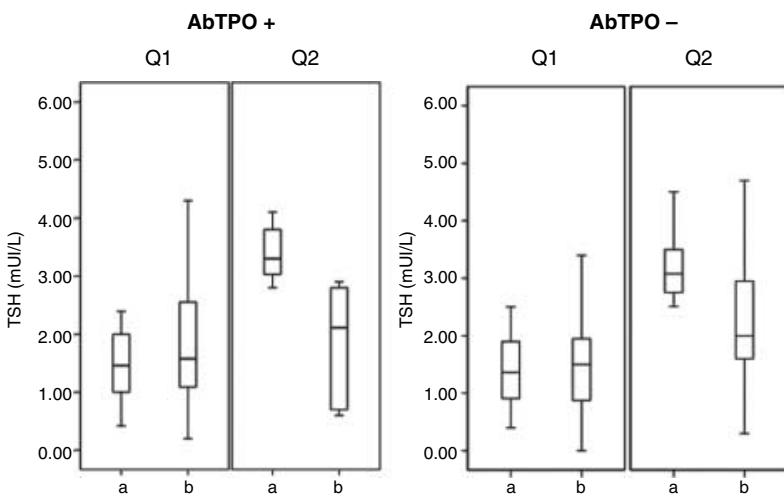

Figure 3 The effect of metformin on serum TSH concentrations by dividing patients of $\mathrm{M}+/ \mathrm{L}-$ group according to the presence or absence of AbTPO. a, baseline; $b$, at the end of follow-up.

replacement therapy (13). Evidence for this TSHlowering effect of metformin was recently extended to overweight women with polycystic ovarian syndrome and hypothyroidism $(14,15)$. In this study, performed on a large series of patients, we confirmed that metformin treatment results in a decrease in serum TSH levels in diabetic patients receiving $\mathrm{L}^{-\mathrm{T}_{4}}$ at substitution doses $(\mathrm{M}+/ \mathrm{L}+$ group).

Furthermore, when patients were stratified according to their basal serum TSH (below $2.5 \mathrm{mIU} / \mathrm{l}$ and between 2.51 and $4.5 \mathrm{mIU} / \mathrm{l})$, a different behavior emerged among the three groups of patients. Serum TSH significantly decreased in all patients in the $\mathrm{M}+/ \mathrm{L}+$ group independently of their basal TSH value. In $\mathrm{M}+/ \mathrm{L}-$ group, only patients with high-normal serum TSH levels showed a significant decrease in TSH. No change in TSH levels was observed in the control group of patients who did not receive either metformin or $\mathrm{L}-\mathrm{T}_{4}$.

The differential TSH-lowering effect of metformin in patients of $\mathrm{M}+/ \mathrm{L}-$ group (i.e. TSH decrease in patients with a high-normal basal TSH but not in those with a low-normal TSH level) occurred independently of the presence of AbTPO. This observation would suggest that the TSH-lowering action of metformin is not related to a direct effect on underlying autoimmune thyroiditis.

The design of the current study does not allow a firm conclusion to be drawn as to a possible explanatory mechanism for this novel and still unclear metformin effect. The early hypothesis that metformin would improve the bioavailability of $\mathrm{L}_{-} \mathrm{T}_{4}$ appears no more plausible following the demonstration that the TSHlowering effect was also observed in patients who were not treated with $\mathrm{L}-\mathrm{T}_{4}$ (13).

As recently reviewed by Duntas et al. (18), an emerging hypothesis to explain the effect of metformin on TSH involves the action of metformin on 5'-AMPactivated protein kinase (AMPK). AMPK regulates cellular metabolism and integrates nutritional and hormonal signals in the hypothalamus, being a central target for both modulation of insulin sensitivity and feedback of thyroid hormones on appetite and energy expenditure. Peripherally, AMPK is dose and time dependently stimulated by tri-iodothyronine $\left(\mathrm{T}_{3}\right)$. In the liver, metformin suppresses hepatic gluconeogenesis by activating AMPK. The opposite effect is observed in the $\mathrm{CN}$ where metformin inhibits hypothalamic AMPK (19). Although few studies on the regulation of the hypothalamic isoforms $(\alpha 1$ and $\alpha 2$ ) of AMPK are available, the results provided by Lopez et al. (20) support the concept that the effects of metformin on hypothalamic AMPK activity can counteract $\mathrm{T}_{3}$ effects at the hypothalamic level. As an alternative hypothesis, the central effect of metformin could be mediated by a reduction of circulating fatty acids (21).

In summary, it should be admitted that although various hypotheses have been proposed, at the moment the mechanisms by which metformin may exert its TSH-lowering effect remain not fully elucidated, and that studies specifically designed to investigate the mechanisms are required. The original finding of our study is that the TSH-lowering effect of metformin can also be observed in euthyroid patients, but only in those with serum TSH in the upper-normal range, independently of the presence of antithyroid antibodies.

Owing to the fact that the normal distribution of TSH is skewed to the left and that $95 \%$ of healthy euthyroid volunteers, screened by the National Academy of Clinical Biochemistry, display a serum level of TSH lower than $2.51 \mathrm{mIU} / \mathrm{l}$ (22), we could assume that a considerable proportion of our patients with a normal but higher than $2.51 \mathrm{mIU} / \mathrm{l}$ serum level of TSH might in fact have a subclinical hypothyroidism. This concept would be in line with the recommendation put forward by some experts (23).

In conclusion, these data strengthen the known TSHlowering effect of metformin in diabetic patients on $\mathrm{L}_{-} \mathrm{T}_{4}$ treatment. We also show, for the first time, a similar TSH-lowering effect in patients with borderline high serum TSH levels.

\section{Declaration of interest}

The authors declare that there is no conflict of interest that could be perceived as prejudicing the impartiality of the research reported.

\section{Funding}

This research did not receive any specific grant from any funding agency in the public, commercial or not-for-profit sector.

\section{References}

1 Wild S, Roglic G, Green A, Sicree R \& King H. Global prevalence of diabetes. Diabetes Care 200427 1047-1053. (doi:10.2337/ diacare.27.5.1047)

2 Canaris GJ, Manowitz NR, Mayor G \& Ridgway EC. The Colorado thyroid disease prevalence study. Archives of Internal Medicine 2000 160 526-534. (doi:10.1001/archinte.160.4.526) 
3 Perros P, McCrimmon RJ, Shaw G \& Frier BM. Frequency of thyroid dysfunction in diabetic patients: value of annual screening. Diabetic Medicine 199512 622-627. (doi:10.1111/j.14645491.1995.tb00553.x)

4 Kordonouri O, Klinghammer A, Lang EB, Grüters-Kieslich A, Grabert M \& Holl RW. Thyroid autoimmunity in children and adolescents with type 1 diabetes: a multicenter survey. Diabetes Care 200225 1346-1350. (doi:10.2337/diacare.25.8.1346)

$5 \mathrm{Wu}$ P. Thyroid disorders and diabetes. It is common for a person to be affected by both thyroid disease and diabetes. Diabetes Selfmanagement 200724 (80-82) 85-87.

6 Feely J \& Isles TE. Screening for thyroid dysfunction in diabetics. BMJ 19791 1678. (doi:10.1136/bmj.1.6179.1678)

7 Bloomagarden ZT. Approaches to treatment of type 2 diabetes. Diabetes Care 200831 1697-1703. (doi:10.2337/dc08-zb08)

8 Shwarts S, Fonseca V, Berner B, Cramer M, Chiang Y-K \& Lewin A. Efficacy, tolerability, and safety of a novel once-daily extendedrealise metformin in patients with type 2 diabetes. Diabetes Care 200629 759-764. (doi:10.2337/diacare.29.04.06.dc05-1967)

9 Abdelghaffar S \& Attia A. Metformin added to insulin therapy for type 1 diabetes mellitus in adolescents. Cochrane Database of Systematic Reviews 200921 CD006691. (doi:10.1002/ 14651858.CD006691.pub2)

10 Moon RJ, Bascombe LA \& Holt RI. The addition of metformin in type 1 diabetes improves insulin sensitivity, diabetic control, body composition and patient well-being. Diabetes, Obesity \& Metabolism 20079 143-145. (doi:10.1111/j.1463-1326.2006.00599.x)

11 Vigersky RA, Filmore-Nassar A \& Glass AR. Thyreotropin suppression by metformin. Journal of Clinical Endocrinology and Metabolism 200691 225-227. (doi:10.1210/jc.2005-1210)

12 Isidro ML, Penìn MA, Nemina R \& Cordido F. Metformin reduces thyrotropin levels in obese, diabetic women with primary hypothyroidism on thyroidism on thyroxine replacement therapy. Endocrine 200732 79-82. (doi:10.1007/s12020-007-9012-3)

13 Cappelli C, Rotondi M, Pirola I, Agosti B, Gandossi E, Valentini U, De Martino E, Cimino A, Agabiti Rosei E \& Castellano M. TSHlowering effect of metformin in type 2 diabetic patients. Diabetes Care 200932 1589-1590. (doi:10.2337/dc09-0273)

14 Morteza Taghavi S, Rokni H \& Fatemi S. Metformin decreases thyrotropin in overweight women with polycystic ovarian syndrome and hypothyroidism. Diabetes $\mathcal{E}$ Vascular Disease Research 2011 8 47-48. (doi:10.1177/1479164110391917)

15 Rotondi M, Cappelli C, Magri F, Botta R, Dionisio R, Iacobello C, De Cata P, Nappi RE, Castellano M \& Chiovato L. Thyroidal effect of metformin treatment in patients with polycystic ovary syndrome. Clinical Endocrinology 201175 378-381. (doi:10.1111/j.13652265.2011.04042.x)
16 Scheen AJ. Drug interactions of clinical importance with antihyperglycaemic agents: an update. Drug Safety: an International Journal of Medical Toxicology and Drug Experience 200528 601-631. (doi:10.2165/00002018-200528070-00004)

17 Wulffelé MG, Kooy A, Lehert P, Bets D, Ogterop JC, Borger van der Burg B, Donker AJ \& Stehouwer CD. Effects of short-term treatment with metformin on serum concentrations of homocysteine, folate and vitamin B12 in type 2 diabetes mellitus: a randomized, placebo-controlled trial. Journal of Internal Medicine $2003 \mathbf{2 5 4}$ 455-463. (doi:10.1046/j.13652796.2003.01213.x)

18 Duntas LH, Orgiazzi J \& Brabant G. The interface between thyroid and diabetes mellitus. Clinical Endocrinology 201175 1-9. (doi:10. 1111/j.1365-2265.2011.04029.x)

19 Lim CT, Kola B \& Korbonits M. AMPK as a mediator of hormonal signalling. Journal of Molecular Endocrinology $2010 \mathbf{4 4} 87-97$. (doi:10.1677/JME-09-0063)

20 López M, Varela L, Vázquez MJ, Rodríguez-Cuenca S, González CR, Velagapudi VR, Morgan DA, Schoenmakers E, Agassandian K, Lage R, Martínez de Morentin PB, Tovar S, Nogueiras R, Carling D, Lelliott C, Gallego R, Oresic M, Chatterjee K, Saha AK, Rahmouni K, Diéguez C \& Vidal-Puig A. Hypothalamic AMPK and fatty acid metabolism mediate thyroid regulation of energy balance. Nature Medicine 201016 1001-1008. (doi:10.1038/ nm.2207)

21 Wiersinga WM, Chopra IJ \& Chua Teco GN. Inhibition of nuclear $\mathrm{T}_{3}$ binding by fatty acids. Metabolism 198837 996-1002. (doi:10. 1016/0026-0495(88)90159-X)

22 Baloch Z, Carayon P, Conte-Devolx B, Demers LM, FeldtRasmussen U, Henry JF, LiVosli VA, Niccoli-Sire P, John R, Ruf J, Smyth PP, Spencer CA \& Stockigt JR; Guidelines Committee, National Academy of Clinical Biochemistry. Laboratory medicine practice guidelines. Laboratory support for the diagnosis and monitoring of thyroid disease. Thyroid 200313 3-126. (doi:10. 1089/105072503321086962)

23 Wartofsky L \& Dickey RA. The evidence for a narrower thyrotropin reference range is compelling. Journal of Clinical Endocrinology and Metabolism 200590 5483-5488. (doi:10. 1210/jc.2005-0455)

Received 12 March 2012

Revised version received 16 May 2012

Accepted 29 May 2012 